\title{
Stereotactic Radiosurgery for Gliomas
}

\author{
Mehmet Tönge and Gökhan Kurt \\ Gazi University, Department of Neurosurgery \\ Turkey
}

\section{Introduction}

The idea of stereotactic radiosurgery (SRS) was first conceived in 1951 by Swedish neurosurgeon Lars Leksell. Focus of his idea was to destroy the surgically inaccessible intracranial tissues or lesions with single fraction high-dose radiation obtained from multiple radiation beams directed to target by stereotactic instruments. He designed the first prototype of gamma knife with Larsson in the light of this idea and performed on his first patient in a nuclear building in 1967. Device was installed at Sophiahemmet hospital in Karolinska - Sweden in the following year. Although only a limited number of patients were treated with gamma knife until 80's, the technique became more popular afterwards and pervaded all around the world. By the time, different radiosurgical devices were developed (Pollock \& Brown, 2005; Stieber \& Ellis, 2005).

SRS was also used in the management of gliomas as well as many other intracranial lesions for years. Some data acquired despite the lack of reported large case series and long term follow up results. Gliomas are believed to arise from neuroglial cells which encounter the most frequent intracranial tumors in different series, constitute $45-60 \%$ of all intracranial tumors. Gliomas have astrocytic, oligodendroglial, ependymal and mixed subtypes. They are also graded I to IV according to histological and clinical behavior. Whereas the grade I and II are accepted as "low grade", the grade III and IV are "high grade" gliomas (Louis et al., 2007). However a portion of low grade gliomas (LGG) are curable by means of current multimodal treatment techniques, the main goal in high grade gliomas (HGG) is the prolongation of survival with a high quality of life as much as possible. Besides, the malignant transformation of LGGs is a well-known issue. Extensive surgical resection followed by radiation therapy (RT) and chemotherapy is the golden standard within most of the treatment protocols; particularly for HGGs. Currently, there are many ongoing clinical studies focused on the role of SRS in the management of gliomas. In most cases, the treatment protocols should be individualized.

\subsection{Radiotherapy versus radiosurgery}

The term "radiotherapy" refers to the treatment of malignant neoplasms and some benign situations by ionizing radiation. The history of RT goes back almost to the exploration of radiation. Many techniques have been developed for performing RT over time which made the RT more accurate and lesion targeted. Recently, techniques such as 3D conformal RT provided by multileaf-collimators and intensity modulated RT are available in addition to conventional RT. External beam radiotherapy (EBRT) is frequently performed in multiple low-dose fractions for post-surgical residuals or recurrences in the management of gliomas. 
A typical RT session is performed with approximately 30 day fractions by a cumulative $\sim 60$ Gy dose except the hypofractioned RT for HGGs. Radiation has prominent effects on tumor tissue like cytotoxicity via early and late DNA damage; inflammatory reactions and edema. Radiosensitivity of the tissue is substantially related with the tissue's proliferation index. Because the normal brain cells are more constant than the tumor cells, the radiation doses between specific ranges tend to effect more on tumor cells. Currently, more conformal and intensity modulated irradiation is preferred to whole brain irradiation in RT protocols.

SRS efforts to effect only to the target lesion while protecting surrounding tissues in a single fractioned high-dose radiation. In contrast to conventional RT, radiosurgery doesn't rely on the increased radiation sensitivity of the target compared with the normal brain. One of the key elements in stereotactic radiosurgery is the use of many radiation fields distributed over space all focusing on a target. This feature minimizes the effect to surrounding normal tissue. Besides, the applied re-irradiation dose and cumulative normalized total doses increase with a change in irradiation technique from conventional RT to radiosurgery retreatment without increasing the probability of normal brain necrosis (Mayer \& Sminia, 2008; Niyazi et al., 2011). The goal of radiosurgery is to arrest the cell division capability of target cells, regardless of the individual cell's mitotic activity and radiosensitivity. Radiosurgery also allows for delayed intratumoral vascular obliteration (Hadjipanayis et al., 2002a). Mechanisms of cell damage are sudden cell death via apoptosis in acute stage; and endothelial proliferation, luminal narrowing and thrombosis in the late stage (Witham et al., 2005). Deliverance of radiation dose in single fraction increases the biological effect of the radiation 2.5 to 3 times compared with multi-fractioned RT which allows decreasing the total treatment dose (Crowley et al., 2006). This means a radiation dose of 15 Gy has similar biological efficacy with approximately 40-45 Gy dose delivered by fractioned RT. However, the edema and radionecrosis caused by irradiation is more relevant in high-dose single fraction deliverance. For that reason, it's not applicable on large intracranial volumes. SRS is almost always a one-day treatment protocol. However SRS has different application protocols, basic steps are the same:

- Establishment of a fiducial system for targeting

- $\quad$ Stereotactic imaging

- Dosimetric planning

- Irradiation

Main differences between conventional RT and SRS are shown in table 1.

\begin{tabular}{lll}
\hline \multicolumn{1}{c}{ RT } & \multicolumn{1}{c}{ SRS } \\
\hline Radiation beam & X ray & $\begin{array}{l}\text { X ray, gamma ray or } \\
\text { charged particles }\end{array}$ \\
Tissue selectivity & $\begin{array}{l}\text { Regarding mitotic activity } \\
\text { and radiosensitivity of the } \\
\text { tissue }\end{array}$ & $\begin{array}{l}\text { Regardless of the mitotic } \\
\text { activity and } \\
\text { radiosensitivity of the } \\
\text { tissue }\end{array}$ \\
Total dose of the treatment & High (45-70 Gy) & Low (10-20 Gy) \\
Fractions & Multiple & $\begin{array}{l}\text { Single or few } \\
\text { Duration of the treatment }\end{array}$ \\
Tumor size & Weeks & $\begin{array}{l}\text { Single day or few days } \\
<3-3.5 \mathrm{~cm} \text { in diameter }\end{array}$ \\
\hline
\end{tabular}

Table 1. Differences between conventional RT and SRS. 


\subsection{Radiosurgical devices}

Radiosurgical devices may be divided into two main groups according to working principles: a) Photon based systems b) Particle based systems. $X$ or gamma rays are used in photon based systems which are substantially capable to penetrate sufficiently into cranium and to generate energy deposition. While $X$ rays are obtained from crashing accelerated electrons on a metallic surface, the gamma rays occur during subatomic particle interactions. They are commonly obtained by courtesy of the natural decay of cobalt ${ }^{60}$ to nickel ${ }^{60}$. Techniques like unifying multiple beams at a target point or intensity modulation are performed to achieve the maximal effect on target due to the potential of these beams to affect the normal tissues on their way.

\subsubsection{Gamma knife}

Main components of a gamma knife are; a gamma knife device with a $\mathrm{Co}^{60}$ source, a stereotactic head frame and a software to make calculations of dose planning. Technology of the device has been developed concurrent with the developments in neuroimaging and computer technology since its first introduction in 1968. In current version of gamma knife, patient undergoes brain imaging following the fixation of a stereotactic head frame onto head. Then, the images are processed with the software and dose planning is performed. Finally, the patient is irradiated by the device. Radiation originating from $\mathrm{Co}^{60}$ source is divided into 201 beams through a hemispheric helmet and targeted into lesion. Beams can be shaped into $4,8,14$ or $18 \mathrm{~mm}$ in diameter radiation balls by using different helmets. Also the shape of the radiation shots can be modified through plugging and shielding techniques thus the eloquent structures like cornea, optic nerves and brainstem can be prevented against adverse radiation effects. Rigid fixation of the head frame by four screws into the outer table of calvarium results in high accuracy with less than $1 \mathrm{~mm}$ deviation at dose planning. Automatic positioning system (APS) enables the computer controlled treatment session without interruption (Pollock \& Brown, 2005). Furthermore, the superimposition of $\mathrm{CT}, \mathrm{MR}$, functional MR, MR tractography, PET scan and angiography images increases the accuracy and efficacy of dose planning (Pantelis et al., 2010). A commonly used term for dose planning is the "marginal dose" which refers to dosage of the radiation measured at peripheral margin of the lesion. For example, the marginal dose of $12 \mathrm{~Gy}$ within $50 \%$ isodose means the central dose lesion received is $24 \mathrm{~Gy}$. A dose planning image is shown in figure 1.

\subsubsection{Linear accelerator (LINAC)}

However the LINAC based RT has been used since 1950s; LINAC was applied to radiosurgery in 80s. Typical current version of a LINAC device consists of a stereotactic head frame, floor stand, 6 megavolts linear accelerator, collimators and high precision attachments. A stream of electrons is accelerated almost to light speed and crash onto a metallic surface which results in production of mainly heat and lesser $X$ rays. These rays are transferred to target point following modulation by multileaf collimators. Multileaf collimators allow to integration of multiple rays coming from different directions at a definite target point (Pollock \& Brown, 2005).

\subsubsection{CyberKnife}

CyberKnife ${ }^{\circledR}$ technology (Accuray, Sunnyvale, CA) was developed by Adler \& colleagues, and was approved by FDA (Food and Drug Administration) for radiation treatment in 2001 
(Adler et al., 1999). CyberKnife system consists of a lightweight LINAC device mounted on an industrial robotic arm and computer software. This structure provides multiaxial movement capability to the device. Real time $X$ ray motion detector cameras monitor the patient's movements during treatment session which minimizes probable accuracy problems. Patient comfort and convenience are served by eliminating invasive frame replacement. In addition, because imaging and planning can occur any time before the radiosurgery procedure, the coordination of radiological resources, physician schedules and patient needs is simplified. Most patients undergo convenient outpatient treatment sessions that are completed within 1 hour, and they complete a treatment plan of two to five fractions in the same number of days (Kuo et al., 2003).

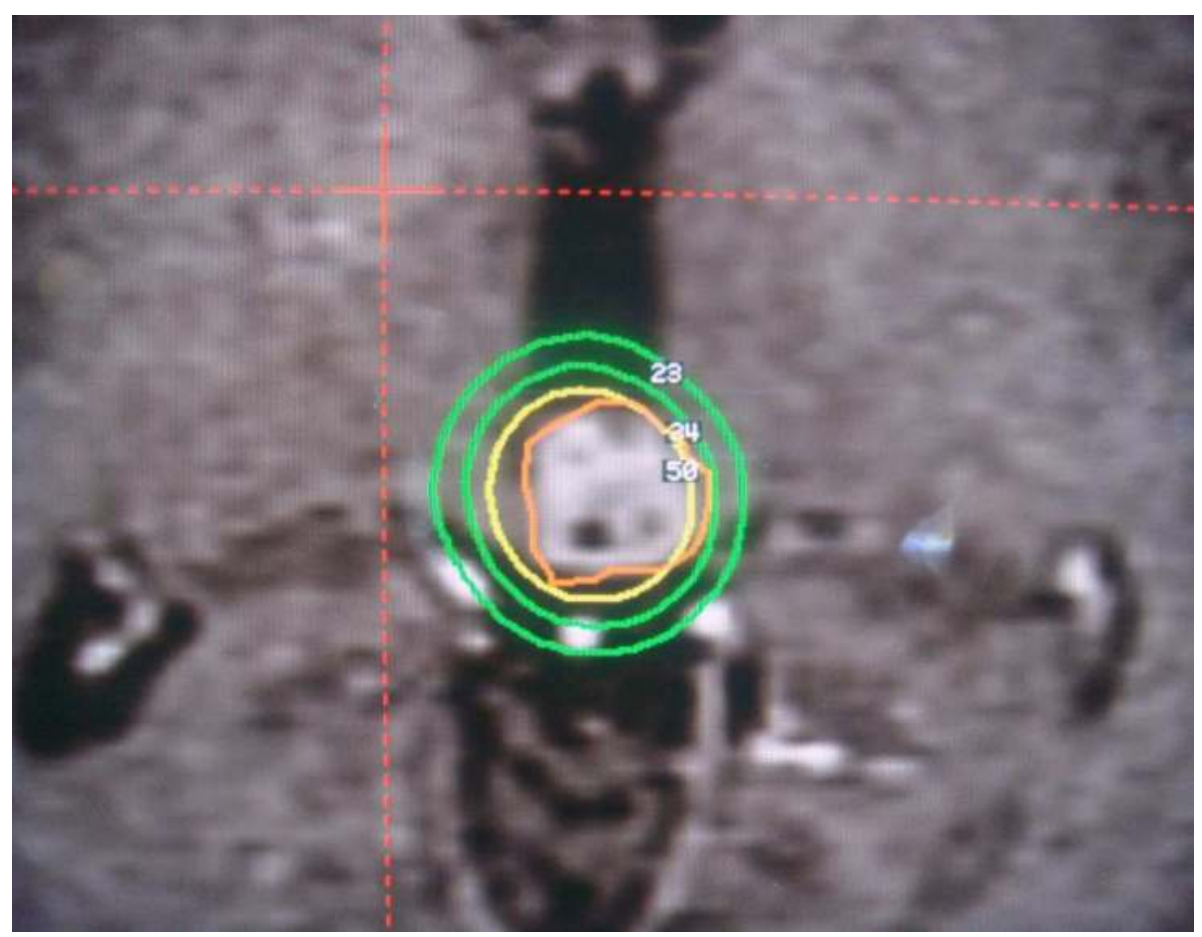

Fig. 1. Snapshot view of gamma knife dose planning on MRI. Orange circle indicates the borders of the tumor, yellow circle indicates the treatment dose of $15 \mathrm{~Gy}$ shot isocenter (within 50\% isodose) and peripheral two green circles indicate 12 and $8 \mathrm{~Gy}$ isodose fields.

\subsubsection{Charged particle beam therapy}

Proton based SRS was pioneered by Kjellberg \& colleagues in the 1960s. This discipline uses either charged protons or helium ions instead of photons. Protons are generated by stripping an atom of its electron and accelerating the residual proton in the magnetic field of a cyclotron or a synch-cyclotron. It's also known as "hadron therapy". A phenomenon called "Bragg peak effect" is very important for a better understanding of fundamentals of proton beam therapy. The pattern of energy distribution of a proton beam consists of an entrance region of a slowly rising dose, a rapid rise to a maximum (Bragg peak) and a rapid fall to 
near zero. This feature provides a moderate entrance dose on the surface structures; a uniform high dose within the target point; and a zero dose beyond the target. A single monoenergetic proton beam irradiates a volume of approximately $1 \mathrm{cc}$. superimposing of multiple beams allows to irradiation of larger lesions. The proton therapy is tended to be performed for larger and more complex lesions in comparison with photon therapy.

Because the relatively longer planning procedure, patient undergoes imaging and treatment on separate days. Beads are implanted into the outer table of the patient's skull and the head of the patient is fixed by a rigid head frame prior to treatment (Chen et al., 2007). Proton beam therapy is performed by only limited number of centers around the world because of the complexity of particle-beam treatment planning, the need for a cyclotron to generate the protons and the expense of these units (Pollock \& Brown, 2005).

\section{Current SRS approaches for glioma}

However the SRS is a relatively young treatment modality, over 400.000 patients were treated with gamma knife all around the world. Currently, there are sufficient data proving the efficacy of SRS on lesions such as arterio-venous malformations, acoustic schwannomas, trigeminal neuralgia and skull base meningiomas. Indications for SRS in gliomas are not definite yet because of the lack of large randomized clinical trials, and multiplicity of gliomas subtypes despite the widespread use (Rejis, 2009).

\subsection{High grade astrocytoma}

High grade astrocytoma (HGA) includes anaplastic astrocytoma (AA), glioblastome multiforme (GBM), giant cell GBM and gliosarcoma according to WHO (World Health Organization) classification system (Louis et al., 2007). Whilst AA is grade III, rests are grade IV tumors. AA and GBM account for $60-65 \%$ of all gliomas (Sloan et al., 2005). The overall survival for untreated GBM is only 2-3 months which increases to mean 9-12 months with addition of gross total resection and RT. Addition of chemotherapy to this modality brings approximately 5 more months. Currently, overall survival for GBM following surgical resection and RT increased to 14-19 months by addition of a latterly popularized chemotherapeutic agent temazolamide (Combs et al, 2005). Median survival for AA is about 23 years with surgical resection, RT and chemotherapy. 5 years survival rate for AA is reported $18 \%$. Most of the AA cases transform into GBM during the course of disease. The treatment approaches for HGA remains palliative, not curative. There is a general consensus for a classification system for evaluating the response of the tumor to SRS treatment (Table 2).

\begin{tabular}{ll}
\hline Terminology & Description \\
\hline Complete response (CR) & $\begin{array}{l}\text { Complete disappearance of enhancing or non- } \\
\text { enhancing tumor }\end{array}$ \\
Partial response (PR) & $>50 \%$ shrinkage of the tumor \\
No change (NC) & $\begin{array}{l}\text { Less than } 50 \% \text { reduction or } 25 \% \text { increase in tumor } \\
\text { volume (stable disease) }\end{array}$ \\
Progressive disease (PD) & $\begin{array}{l}>25 \% \text { increase in volume of the enhancing or non- } \\
\text { enhancing tumor }\end{array}$ \\
\hline
\end{tabular}

$(C R+P R+N C=$ Tumor Control Rate $(T C R), C R+P R=$ Effectiveness $)$

Table 2. Classification of responsiveness of the tumor to SRS treatment. 
A review by Yoshikawa et al on malignant glioma included seven clinical studies of RT plus SRS comparing with four clinical studies of RT only showed 20.2 and 11.1 months median overall survivals, respectively. Also the progression free survival (PFS) is found a median 281 days for SRS and 130 days for RT group (Yoshikawa et al., 2006). (Table 3).

\begin{tabular}{|c|c|c|c|c|c|c|}
\hline Group & First author, year & Pathology & $\begin{array}{c}\text { Number } \\
\text { of } \\
\text { patients }\end{array}$ & $\begin{array}{c}\text { SRS } \\
\text { modality }\end{array}$ & $\begin{array}{c}\text { Median } \\
\text { survival } \\
\text { after } \\
\text { diagnosis } \\
\text { (months) }\end{array}$ & $\begin{array}{c}\text { Mean } \\
\text { survival } \\
\text { of the } \\
\text { group } \\
\text { (months) }\end{array}$ \\
\hline & Masciopinto, 1995 & GBM & 31 & $\overline{\text { LINAC }}$ & 9.5 & \\
\hline & Gannett, 1995 & $\begin{array}{l}\text { Malignant } \\
\text { glioma }\end{array}$ & 30 & LINAC & 13.9 & \\
\hline & Kondziolka, 1997 & GBM & 64 & $\begin{array}{l}\text { Gamma } \\
\text { knife }\end{array}$ & 26 & \\
\hline \multirow[t]{5}{*}{ SRS } & Shrieve, 1999 & GBM & 78 & LINAC & 19.9 & 20.2 \\
\hline & Nwokedi, 2002 & GBM & 31 & $\begin{array}{l}\text { Gamma } \\
\text { knife }\end{array}$ & 25 & \\
\hline & Prisco, 2002 & $\begin{array}{l}\text { Malignant } \\
\text { glioma }\end{array}$ & 15 & $\begin{array}{c}\text { Gamma } \\
\text { knife }\end{array}$ & 21.4 & \\
\hline & Yoshikawa, 2006 & GBM & 18 & CyberKnife & 20.7 & \\
\hline & Curran, 1993 & $\begin{array}{l}\text { Malignant } \\
\text { glioma }\end{array}$ & 1578 & $\mathrm{NA}^{*}$ & 11.3 & \\
\hline \multirow[t]{3}{*}{ RT } & Nwokedi, 2002 & GBM & 33 & NA & 13 & 11.1 \\
\hline & Prisco, 2002 & $\begin{array}{l}\text { Malignant } \\
\text { glioma }\end{array}$ & 17 & NA & 11.6 & \\
\hline & Laws, 2003 & GBM & 413 & NA & 10.2 & \\
\hline
\end{tabular}

Table 3. Review of studies comparing SRS with conventional RT by means of survival rates. (NA*: Not available)

Current multimodal treatment regimen for HGA includes a diagnostic or cytoreductive surgery followed by boost RT. For that reason, it's not so possible to meet with cases only treated with SRS without RT. Preliminary results of cases treated only with SRS for HGA suggested poor outcomes (Crowley et al., 2006). Certain indications and guidelines for patient selection criteria is not established yet on SRS for HGA. However long term outcome results of randomized controlled trials for SRS in HGA is not well reported yet, some helpful criteria standing out are described below.

\subsubsection{Timing of SRS}

Timing of SRS for HGAs is controversial. While some of the authors have performed SRS for residual disease following surgical resection as a boost or in combination with RT, others have tended to perform as salvage for recurrence following RT. ASTRO (The American Society for Therapeutic Radiology and Oncology) has reported a comprehensive evidencebased review on SRS for HGA in 2005. They found level I-III evidence that the use of radiosurgery boost followed by RT and BCNU doesn't confer benefit in terms of overall survival, local tumor control or quality of life as compared with RT and BCNU. 
Furthermore, they pointed that the boost radiosurgery is associated with increased long term toxicity. They also reported that there is not sufficient evidence yet to show the effectiveness of SRS on recurrent or progressive malignant glioma (Anker et al., 2010; Tsao et al., 2005).

A multicentric study including 46 patients on CyberKnife comparing the use as a boost with salvage reported median overall survival of 11.5 and 21 months for GBM respectively. This study also suggested no significant difference of survival between boost SRS and not to perform SRS (Villavicencio et al., 2009). In another study including 48 GBM patients, the use of SRS as boost or salvage was related with median survival of 15.1 and 17.1 months respectively. Difference in survivals was also statistically significant in this study (Pouratian et al., 2009). Contrarily, median survivals for GBM was found 10 and 16.7 months with boost and salvage SRS respectively in another study including 51 GBM patients in which the difference was statistically not meaningful (Hsieh et al., 2005). A study including 32 recurrent GBM patients treated with LINAC radiosurgery following conventional approach (surgery + RT) reported median 10 months of PFS following initial conventional treatment. SRS has contributed an additional 5 months of PFS to patients and a median 22 months of overall survival has been achieved. Survival rates of the study for $1^{\text {st }}, 2^{\text {nd }}$ and $3^{\text {rd }}$ years are $88 \%, 41 \%$ and $19 \%$, respectively (Combs et al., 2005). Besides, current studies on efficacy of repetitive SRS for multiple recurrences suggest no benefit on overall survival (Yoshikawa et al., 2006).

\subsubsection{Tumor volume}

Increased tumor volume is associated with increased complication rates in SRS. Treatment dose should be decreased while tumor volume increases to avoid the complications such as radionecrosis and edema; which weakens the effectiveness of the treatment (Combs et al., 2007; Niyazi et al., 2011). Despite the lack of a definite threshold, SRS is not recommended for lesions larger than $3 \mathrm{~cm}$ diameter. Kong et al have reported the $<10 \mathrm{ml}$ tumor volume as the most important prognostic factor for SRS for malignant glioma in a series of 114 patients (Tsao et al., 2005). While adverse radiation effects occur rarely for tumors under $10 \mathrm{ml}$ volume, Cho et al reported a high late complication rate of $30 \%$ for treatment of mean $30 \mathrm{ml}$ tumors with mean 17 Gy (Cho et al., 1999).

\subsubsection{Histological grade}

HGAs are classified as grade III and IV tumors. Various studies suggested the significant effect of histological grade on SRS treatment outcome. Yoshikawa et al reported an effectiveness rate and TCR of $27.2 \%$ and $63.3 \%$ for GBM respectively at least four weeks after SRS. Nevertheless, they found $18.2 \%$ and $45.5 \%$ for AA. Another study reported by Kong et al suggested a significant increase in overall median survival rate with SRS for GBM group and no difference in AA group as compared with control group (Kong et al., 2008). These results suggest that SRS may have a potential benefit on grade IV HGA.

\subsubsection{Tumor location and extent of surgical resection}

Extent of surgical resection and effective post-operative RT are important prognostic factors for HGA. However, extensive surgical resection is not always possible particularly for tumors located in eloquent areas as optic nerves, brainstem and midbrain. Surgical 
approach generally remains limited with biopsy for these locations. While the median survival is only 6 months in HGA patients who underwent biopsy followed by RT and SRS. The survival rises up to 21 months in patients who undergo gross total resection in anytime during the course of disease (Villavicencio et al., 2009). Pouratian et al reported more favorable overall survival rates following SRS in RTOG (Radiation Therapy Oncology Group) Class-III patients (patients who underwent extensive surgical resection and without need for steroids at the time of SRS). Adjuvant treatments like RT and chemotherapy come forward when the surgical resection is not feasible. Different biological structures have different radiation limits. For example, the calculated cumulative radiation maximum point dose limits for lens is $10 \mathrm{~Gy}$, retina $50 \mathrm{~Gy}$ and optic nerve, chiasm and brainstem is $55 \mathrm{~Gy}$. Biological equivalents of these limits are lesser for SRS (lens: 1-2 Gy, optic nerve \& chiasm: 8-10 Gy and brainstem: 12 Gy) (Sharma et al. 2008). Unfortunately, a cumulative dose of $>60$ Gy is required for effective irradiation HGA. This requirement let the physicians to combine lower dose RT with SRS to achieve an effective treatment. A median 18 months survival was achieved for GBM patients within eloquent locations with combination of 50 Gy RT, 10 Gy SRS and temazolamide following biopsy (Oermann et al., 2010). Contrarily, no significant difference was observed by means of overall survival rates in another study comparing RT only with RT plus gamma knife following biopsy for unresectable GBMs (Kong et al., 2006). Interestingly, the Karnofsky performance scores (KPS) of RT+SRS group has been found to be significantly higher than the RT only group in first 3 months follow-ups.

\subsubsection{Tumor control and functional outcome}

Because the recurrences typically occur within $2-3 \mathrm{~cm}$ of the tumor resection bed in $63-90 \%$ of the patients, local control of the tumor has a particular importance in the management of HGA. Preliminary results for HGA suggest that SRS increases local tumor control rate, progression free and overall survival, and quality of life (Blomquist et al., 2005; Gerosa et al., 2003). It's shown that the SRS delays neurological deterioration in HGA and provides better KPS during the course of the disease (Jagannathan et al., 2004). Pre-SRS $>90$ KPS is also associated with better overall survival.

\subsubsection{Other aspects of SRS for HGA}

SRS is preferable for patients with progressive or recurrent disease following initial surgical resection and RT if re-resection is not feasible. However, a significant difference has been shown on median survival between patients responsive to initial RT and irresponsive (15.8 vs. 7.3 months, respectively) (Patel et al., 2009). There are not definite evidences for the role of age and gender as prognostic factors.

Current treatment modality for HGA includes surgical resection as extensive as possible, post-operative RT and administration of temazolamide (Sathornsumetee \& Rich, 2008). SRS is considerable only for a limited number of patients with particularly WHO grade IV, recurrent, well circumscribed and small lesions as a palliative.

\subsection{Low grade astrocytoma}

Low grade astrocytoma (LGA) includes grade I (subependymal giant cell astrocytoma and pilocytic astrocytoma) and grade II (pilomyxoid, diffuse astrocytoma and pleomorphic xanthoastrocytoma) tumors according to WHO classification system (Louis et al., 2007). 
LGA accounts for $15 \%$ of all primary CNS tumors in adult (Heppner et al., 2005). However the peak age for LGA is 35; the pilocytic astrocytoma is more frequent in pediatric population. Gross total resection is the golden standard in the treatment of LGA. RT is especially preferred in older patients underwent subtotal resection (Morantz, 2001). Survival rate for LGA is inversely correlated with histologic grade and age. While the 10 year median survival for pilocytic astrocytoma in pediatric age is above $90 \%$, it's about $7 \%$ for diffuse astrocytoma patients in sixth decade (Henderson et al. 2009). A brief review of available studies on effectiveness of SRS for LGA is given below (Table 4).

\begin{tabular}{|c|c|c|c|c|c|c|c|c|}
\hline $\begin{array}{l}\text { First author / } \\
\text { Year }\end{array}$ & $\begin{array}{c}\text { Number } \\
\text { of } \\
\text { patients }\end{array}$ & Tumor type & $\begin{array}{l}\text { Med } \\
\text { age }\end{array}$ & $\begin{array}{c}\text { Med } \\
\text { target } \\
\text { volume } \\
(\mathrm{ml})\end{array}$ & $\begin{array}{l}\text { Med } \\
\text { dose } \\
(\mathrm{Gy})\end{array}$ & $\begin{array}{l}\text { Med } \\
\text { follow } \\
\text { up } \\
\text { (mns) }\end{array}$ & PFS or PFS rate & TCR \\
\hline $\begin{array}{c}\text { Hadjipanayis, } \\
2002 a\end{array}$ & 12 & $\begin{array}{c}\text { Fibrillary } \\
\text { astrocytoma }\end{array}$ & 25 & 4.6 & 15 & 52 & $67 \%$ for $52 \mathrm{mns}$ & NA \\
\hline $\begin{array}{l}\text { Hadyipanayis, } \\
2002 b\end{array}$ & 37 & Grade I & 14 & 3 & 15 & 28 & NA & $68 \%$ \\
\hline Boethius, 2002 & 19 & Grade I & 10.6 & 2.2 & 10 & 56.4 & NA & $94.7 \%$ \\
\hline $\begin{array}{l}\text { Hadjipanayis, } \\
2003\end{array}$ & 49 & $\begin{array}{l}\text { PA (n:37), } \\
\text { Grade II } \\
\text { (n:12) }\end{array}$ & $\begin{array}{c}14 \\
\text { (PA), } \\
25 \\
\text { (Grade } \\
\text { II) }\end{array}$ & 3.3 & 15 & 32 & NA & $67 \%$ \\
\hline Heppner, 2005 & 49 & $\begin{array}{c}\text { Grade I and } \\
\text { II }\end{array}$ & 27 & 2.4 & 15 & 63 & $44 \mathrm{mns}$ & NA \\
\hline Wang, 2006 & 21 & $\begin{array}{c}\text { Grade I and } \\
\text { II }\end{array}$ & 20 & 2.4 & 14.5 & 67 & $65 \%$ (10 year) & NA \\
\hline Yen, 2007 & 20 & $\begin{array}{c}\text { PA (n:5), } \\
\text { Non-PA } \\
\text { (n:5), NHP* } \\
\text { (n:10) }\end{array}$ & 19.1 & 2.5 & 12.8 & 78 & NA & $80 \%$ \\
\hline Kano, 2009a & 14 & Grade I & 32.3 & 4.7 & 13.3 & 36.3 & $\begin{array}{c}89.3 \%, 31.5 \% \text { and } \\
31.5 \% \text { for } 1,3 \text { and } \\
5 \text { years }\end{array}$ & NA \\
\hline Kano, 2009b & 50 & Grade I & 10.5 & 2.1 & 14.5 & 55.5 & $\begin{array}{c}91.7 \%, 82.8 \% \text { and } \\
70.8 \% \text { for } 1,5 \text { and } \\
10 \text { years }\end{array}$ & NA \\
\hline $\begin{array}{c}\text { Henderson, } \\
2009\end{array}$ & 12 & $\begin{array}{c}\text { Grade I and } \\
\text { II }\end{array}$ & 17.4 & 4.4 & 13 & 48.2 & $75 \%$ for $48 \mathrm{mns}$ & NA \\
\hline Park, 2011 & 6 & SEGA $^{* *}$ & 16.5 & 2.75 & 14 & 73 & NA & $67 \%$ \\
\hline
\end{tabular}

Table 4. Review of available literature on SRS treatment for LGA. (NHP*: Not histologically proven, SEGA**: Subependymal giant cell astrocytoma, NA: Not available, PA: Pilocytic astrocytoma, TCR: Tumor control rate.) 


\subsubsection{Timing of SRS}

SRS may either be performed alone or as a boost in combination with RT for residual tumor in early post-operative period; or as salvage treatment at the time of recurrence. Whether or not to perform and when to perform is the moot point. Boost SRS concurrent with RT was found to cause more adverse radiation effect in comparison with salvage (adjuvant) SRS (Wang et al., 2006). 10 year median survival rate was found $88.9 \%$ for PA patients underwent partially resection or biopsy followed by SRS alone as the principal treatment. The ratio was also found $44.5 \%$ for PA patients received delayed SRS for recurrent disease. Delayed SRS for recurrent tumor seems to be associated with poor PFS (Kano et al., 2009b). On the other hand, it doesn't seem so reasonable to make a generalization for timing of SRS because the tumors highly tended to recur already have poor prognosis. Another study reported TCR of 56.3 months for boost SRS versus $44.4 \%$ for late SRS. However, this difference was not statistically significant (Park et al., 2010). The beginning of shrinkage following SRS occurs between a median 13-16 months (range; 3-92.4) for LGA (Yen et al., 2007; Kano et al. 2009a \& 2009b). In case of progression, the mean time from SRS to the beginning of progression has been found about 23 months (Hadjipanayis et al., 2002a). That's why the patients should be periodically followed-up in a long time period. Despite the lack of large series on effectiveness of repetitive SRS for recurrent LGA; achievement of effective tumor control has been reported for sporadic cases. More studies are needed intended to timing of SRS for LGAs. Available literature suggests better tumor control for residual PA with early SRS.

\subsubsection{Tumor location and pattern}

Even though the primary treatment for LGA is the surgical resection, SRS following pathological diagnosis serves as an option for tumors located in eloquent areas and for unresectable tumors. However, the treatment dose should be diminished to avoid damage to surrounding tissues for tumors in close proximity to eloquent tissues, which results in reduction of effectiveness of the treatment. SRS is preferable instead of whole brain irradiation for LGA because of the locally invasive nature of these tumors.

Brainstem gliomas account for less than $2 \%$ of adult and $10-20 \%$ of pediatric age glial tumors. Although $52-69 \%$ of brainstem gliomas are low grade, they carry greater potential for malignant transformation with respect to other locations (Bricolo, 2009). 80\% TCR during 78 month follow-up was reported in a series of 20 unresectable focal brainstem gliomas with gamma knife with mean 12.8 Gy doses (Yen et al., 2007). Another study comparing TCR for LGA between brainstem and other locations reported 59\% and 67\% TCR, respectively (Hadjipanayis et al., 2003). Progression rate following SRS was also found $45 \%$ for brainstem versus $10 \%$ for other locations. Major reasons for lower success rate of SRS for brainstem gliomas are the more aggressive nature of tumor at this location and the requirement of dose reduction. Unresectable low grade optic glioma may also benefit from fractionated SRS. Effective TCR and prevention of progressive visual symptoms were reported for optic gliomas (Kurt et al., 2010).

LGAs may include solid or cystic components. Better response to the SRS for solid LGA was reported in various series. Furthermore, half of the progressive patients have only cyst enlargement without solid enlargement. TCR for pure solid tumors was $84 \%$ in a study including both solid and cystic tumors with overall 68\% TCR (Hadjipanayis et al., 2002a). 1, 
3 and 5 year PFS rates were found $75 \%, 50 \%$ and $50 \%$ for solid, and $88.9 \%, 17.8 \%$ and $0 \%$ for mixed solid-cystic tumors respectively in a study (Kano et al, 2009a). Another study reported 3, 5 and 10 year PFS rates of $100 \%, 94.4 \%$ and $85 \%$ for solid, and $53.1 \%, 21.3 \%$ and $0 \%$ for mixed solid-cystic tumors respectively (Kano et al., 2009b). Peripheral contrast enhancement and cystic changes on MRI are related with poor prognosis (Park et al., 2010). SRS may also be performed for multicentric LGA, but the prognosis of multicentric tumors is poorer than the solitary tumors (Hadjipanayis et al., 2002a).

\subsubsection{Tumor volume and radiation dose}

Administration of maximal dose to a minimum volume without damaging normal tissue is one of the major goals of SRS. The probability of direct and indirect surrounding tissue damage due to radionecrosis and edema increases in proportion to the tumor volume and radiation dose. However the SRS dose above 15Gy is known as a good prognostic criterion for LGA, high TCR rate $(94.7 \%)$ with low dose SRS for PA has also been reported (Boethius et al., 2002). Tumor volume less than 6-8 cc is significantly related with better prognosis (Park et al, 2010). Despite the lack of a definite dose range for LGA, doses ranging between 10-15 Gy are currently used. Dose modification or reduction should be considered for patients who have undergone fractionated cranial RT before SRS (Wang et al., 2006).

\subsubsection{Histological grade and age}

Pilocytic astrocytoma has a better prognosis than grade II astrocytomas. Grade II astrocytoma carries a potential to transform into malignant glioma. Pilocytic astrocytoma also has better prognosis in children than in adults. Median 1, 3 and 5 year PFS rates are 91.7\%, 82.8\% and $70.8 \%$ for pediatric PA; and $83.8 \%, 31.5 \%$ and 31.5 for adult PA respectively (Kano et al., 2009a, 2009b). SRS as an alternate to RT has been found very effective for PA patients in whom the re-resection is not feasible or with early recurrence. But the place of SRS in multimodal treatment of grade II astrocytoma is controversial. 91.3\%, $54.1 \%$ and $37.1 \%$ PFS rates for 1, 5 and 10 years respectively has been reported for radiosurgical treatment of residual or recurrent grade II astrocytomas (Park et al, 2010). More studies are needed for determining definite indications and criteria of SRS for LGA. Prognostic factors of SRS for LGA are listed below (Table 5).

\begin{tabular}{|c|c|}
\hline Good prognosis & Poor prognosis \\
\hline Pilocytic astrocytoma & Grade II astrocytoma \\
\hline Solid, well circumscribed tumors & Cystic tumors \\
Volume $<6-8 \mathrm{cc}$ & Larger volume \\
Teenagers & Age $<10$ year or $>70$ year \\
Solitary tumors & Multicentric tumors \\
History of long term effective RT & History of unsuccessful RT \\
Effective SRS dose & Lower SRS dose \\
No contrast enhancement on MRI & Peripheral contrast enhancement \\
\hline
\end{tabular}

Table 5. Prognostic factors of SRS for LGA 
Finally, the best candidates for SRS treatment are the pilocytic astrocytomas if previously resected, well circumscribed, and located in critical or deep areas or re-resection is not feasible, or if there is an early recurrence.

\subsection{Ependymoma}

While ependymomas are classified as grade II in WHO grading system, the anaplastic ependymomas are grade III tumors. However the local tumor control has a great importance for ependymoma management, high propensity of seeding through ventricular system and central canal serves as a problem. The most prominent poor diagnostic factor is the spinal metastasis for ependymomas. Current treatment modality includes surgical resection followed by RT. Chemotherapy is also indicated for anaplastic ependymomas. Better local tumor control for ependymomas with SRS has been reported in limited number of preliminary studies. Results with boost SRS + RT are better than SRS for late recurrences conversely to other gliomas. There is a proportion between time to recurrence and success rate for adjuvant SRS. 100\% TCR was found at a mean 21 months follow up in a series of 22 anaplastic ependymoma patients following adjuvant SRS (Jawahar et al., 1999). But $44 \%$ patients recurred at a distant site of the CNS in further follow ups. Definite predictors of better prognosis for SRS treatment for ependymomas are; (Kano et al., 2009d, 2010)

- Absence of spinal metastasis

- Lower tumor volume

- Time interval between RT and recurrence $>18$ months

- Homogeneous contrast enhancement on MRI for low grade ependymomas

Interestingly, no significant relation was found between the grade of the tumor and PFS. SRS seems a valuable treatment option for local control of recurrent or residual ependymomas. On the other hand, the distant seeding and recurrences of the tumor is a pain in the neck (Krieger \& McComb, 2009; Lo et al., 2006a, 2006b).

\subsection{Oligodendroglioma and mixed oligoastrocytoma}

Only seldom studies are available regarding to the effectiveness of SRS for oligodendroglioma and oligoastrocytoma in current literature. A study on SRS for oligodendroglioma reported 5 and 10 year overall survival rates of $90.9 \%$ and $68.2 \%$ for grade II, and $52.1 \%$ and $26.1 \%$ for grade III oligodendroglioma, respectively (Kano et al., 2009c). Tumor volume less than 15 cc and patients with 1p19q gene deletion are related with better outcome. Another study on SRS including oligodendroglioma and oligoastrocytoma patients suggested that the younger age is also associated with better outcome (Sarkar et al., 2002). Further studies are needed to assess the effectiveness of SRS for these entities.

\section{Complications of SRS}

Adverse radiation effects due to SRS include focal edema and radionecrosis. These effects correspondingly intensify with the tumor volume and radiation dose and found more frequently in patients who received boost SRS concurrently with RT. Frequency of adverse radiation effects range between 0 to $40 \%$ in different series, albeit it's uncommonly more than $5 \%$. These effects are usually completely reversible with anti-edema medications and rarely results in permanent neurological complications. Previous irradiation history should 
be considered particularly for lesions located in eloquent areas and dose should be reduced. Aggressive irradiation might result in excessive edema and radionecrosis requiring additional procedures such as emergent decompression or shunting (Smith et al., 2008).

Radiation induced tumors is another potential complication of SRS. Several sporadic reports of GBM formation in long term following high dose SRS are already present. However long term follow up is needed to assess this potential, incidence seems less than 1:100.000 for now (Berman et al., 2007; Salvati et al., 2003).

\section{Case illustrations}

Case 1. 25 years old male presented with progressive headache. Cranial MRI showed an intraxial mass lesion in close proximity to pineal region. Patient refused biopsy and considered for gamma knife. Mass disappeared at 6th month post-SRS and didn't recur during 6 year follow ups. (Figure 2)

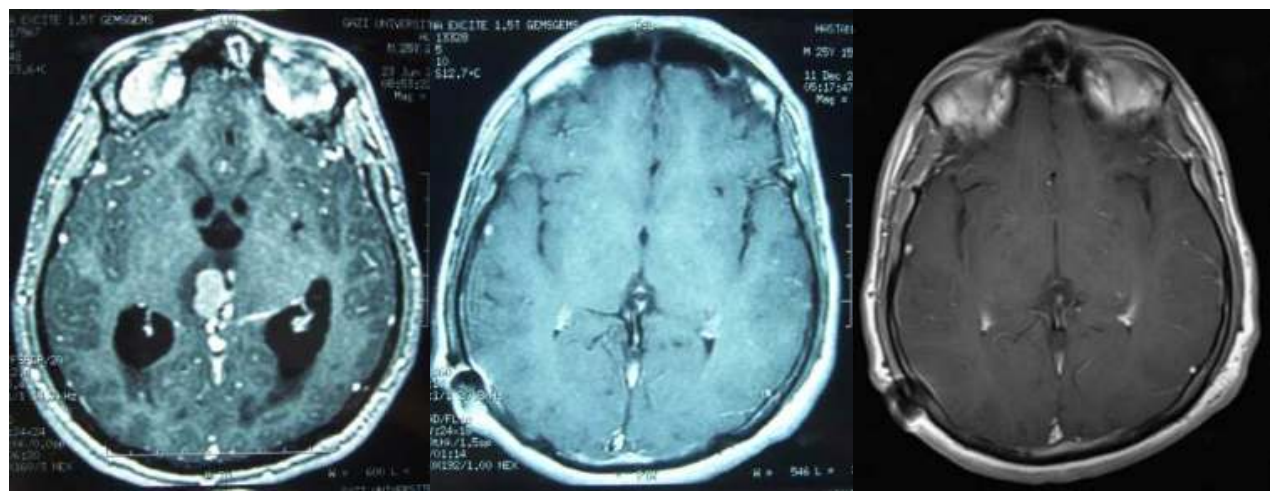

Fig. 2. Left: pre-SRS axial contrast enhanced MRI view. Middle: 6 months after SRS. Right: 6 years after SRS.

Case 2. 37 years old male presented with complete loss of vision at the right eye and progressive loss of vision on the left eye for months. MRI scan revealed an optic glioma located on the right half of the chiasm. Patient underwent low dose fractionated SRS to avoid the damage to the chiasm and optic nerve. (Figure 3) Patient was followed up 66 months following SRS, and neither tumor progression, nor visual deterioration was seen. (Figure 4) 


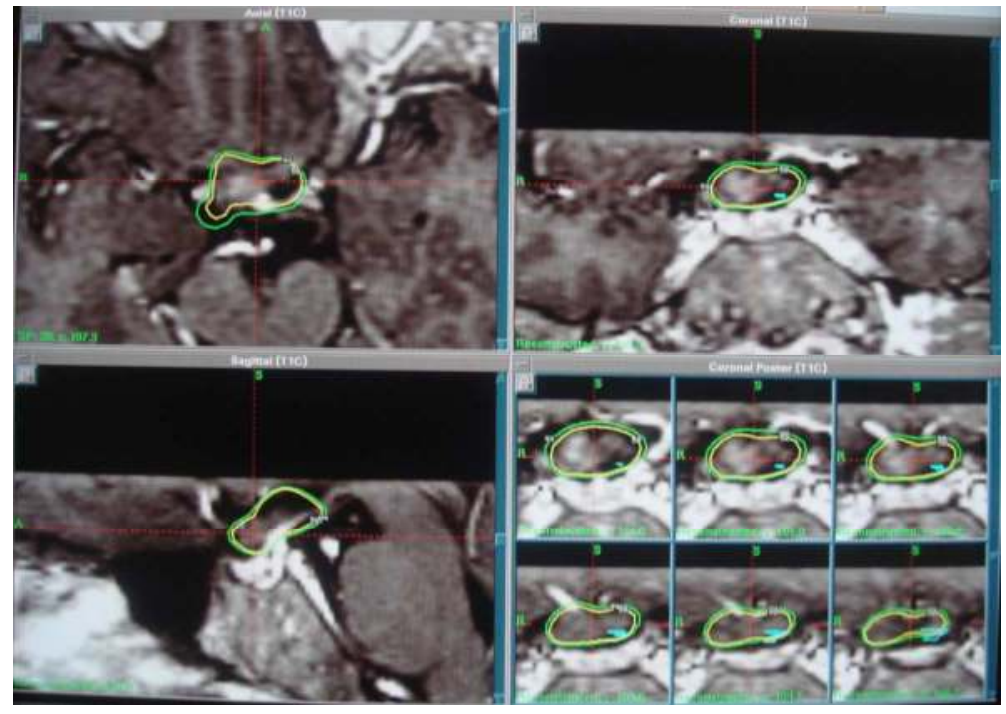

Fig. 3. Gamma knife dose planning.

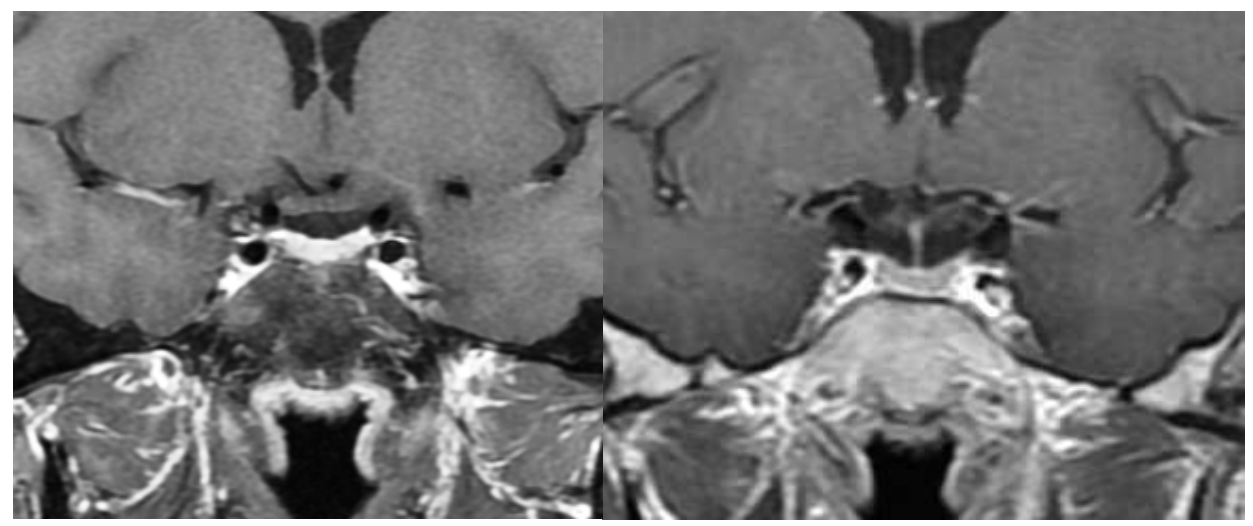

Fig. 4.39 (left) and 66 (right) months after SRS; complete disappearance of the tumor.

Case 3. 52 years old male presented with slight right hemiparesis, numbness and progressive headache. Multiple intracranial lesions were detected on MRI scan. Stereotactic biopsy of the tumor revealed GBM. Patient received conventional RT followed by temazolamide immediately after pathologic diagnosis. Regression in two of three tumors and progression in one tumor located at the left trigonal region was found 6 months after diagnosis. Thereupon, adjuvant SRS was performed to the progressive tumor. Nevertheless, tumor kept progressing and required decompressive resection 6 months after SRS. (Figure 5) 

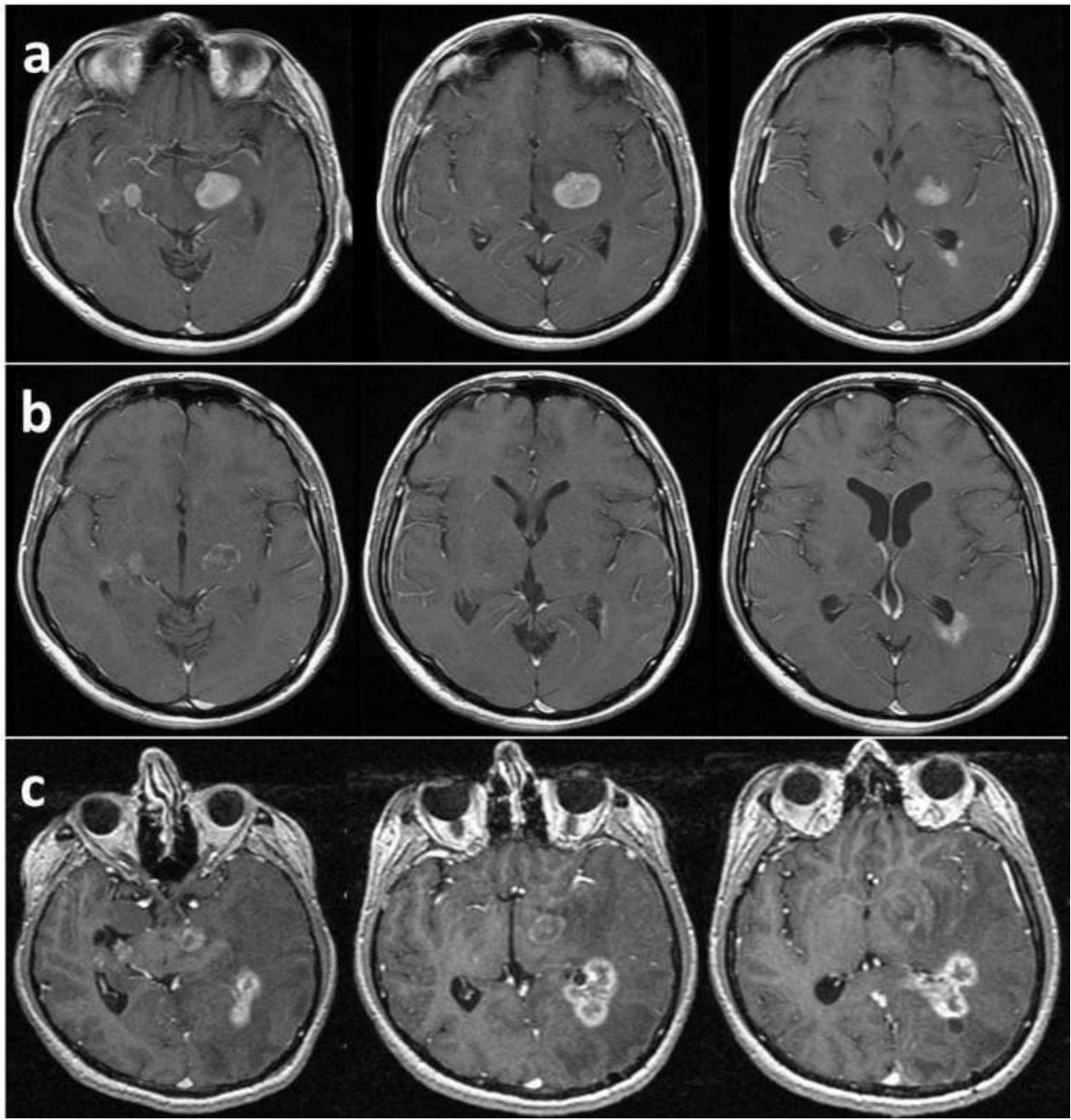

Fig. 5. a) MRI scans of the patient at the time of initial diagnosis. b) Pre-SRS MRI scan of the patient following stereotactic biopsy, RT and temazolamide. c) 6 months after SRS; progressive tumor is visible at the left trigon

\section{Conclusion}

Although the guideline indications of SRS in the management of gliomas are not definite yet, favorable results are being reported especially for pilocytic astrocytoma and ependymoma. SRS also makes significant contributions to multimodal treatment modality of GBM as an adjuvant, as well. SRS might safely be used for carefully selected patients with low complication rates and high efficacy. Many prudential studies are also conducted in this growing field of neurosurgery. Successful results were reported for combination of SRS with agents like thalidomide, marimastat and gefitinib, hyperbaric oxygen therapy or with 
genetic treatment modalities like adenoviral or herpetic viral vectors ( Kohshi et al., 2007; Larson et al., 2002; Lee et al., 2006; Niranjan et al., 2000; Schwer et al., 2008; Xu et al., 2006). As a result, the SRS is a promising adjuvant technique for glioma treatment.

\section{References}

Adler, J.R.; Murphy, M.J.; Chang, S.D. \& Hancock, S.L. (1999). Image guided robotic radiosurgery. Neurosurgery, 44:1299-1307

Anker, C.J.; Hymas, R.V.; Hazard, L.J.; Boucher, K.M.; Jensen, R.L. \& Shrieve, D.C. (2010). Stereotactic radiosurgery eligibility and selection bias in the treatment of glioblastoma multiforme. J. Neurooncol., 98:253-263

Berman, E.L.; Eade, T.N.; Brown, D.; Weaver, M.; Glass, J.; Zorman, G. \& Feigenberg, S.J. (2007). Radiation-induced tumor after stereotactic radiosurgery for an arteriovenous malformation: Case report. Neurosurgery, 61:E1099

Blomquist, E.; Bjelkengren, G. \& Glimelius, B. (2005). The potential of proton beam radiation therapy in intracranial and ocular tumors. Acta Oncologica, 44:862-870

Boethius, J.; Ulfarsson, E.; Rahn, T. \& Lippitz, B. (2002). Gamma knife radiosurgery for pilocytic astrocytomas. J. Neurosurg., 97:677-680

Bricolo, A. (2009). Brainstem tumors, In: Practical Handbook of Neurosurgery from Leading Neurosurgeons, M. Sindou (ed.), Vol.2:349-372, Springer-Verlag/Wien, ISBN 978-3211-84819-7, Mörlenbach, Germany

Chen, C.C.; Chapman, P.; Petit, J. \& Loeffler, J. (2007). Proton radiosurgery in neurosurgery. Neurosurg. Focus, 23 (6):E5

Cho, K.H.; Hall, W.A.; Gerbi, B.J.; Higgins, P.D.; McGuire, W.A. \& Clark, H.B. (1999). Single dose versus fractionated stereotactic radiotherapy for recurrent high-grade gliomas. Int. J. Radiation Oncology Biol. Phys., 45:1133-1141

Combs, S.E.; Debus, J. \& Schulz-Ertner, D. (2007). Radiotherapeutic alternatives for previously irradiated recurrent gliomas (review). BMC Cancer, 7:167

Combs, S.E.; Widmer, V.; Thilmann, C.; Hof, H.; Debus, J. \& Schulz-Ertner, D. (2005). Stereotactic radiosurgery (SRS); treatment option for recurrent glioblastoma multiforme (GBM). Cancer, 104:2168-2173

Crowley, R.W.; Pouratian, N. \& Sheehan, J.P. (2006). Gamma knife surgery for glioblastoma multiforme. Neurosurg. Focus, 20 (4):E17

Gerosa, M.; Nicolato, A. \& Foroni, R. (2003). The role of gamma knife radiosurgery in the treatment of primary and metastatic brain tumors. Curr. Opin. Oncol., 15:188-196, ISSN 1040-8746

Hadjipanayis, C.G.; Kondziolka, D.; Flickinger, J.C. \& Lunsford, L.D. (2003). The role of stereotactic radiosurgery for low-grade astrocytomas. Neurosurg. Focus, 14 (5): Article 15

Hadjipanayis, C.G.; Kondziolka, D.; Gardner, P.; Niranjan, A.; Dagam, S.; Flickinger, J.C. \& Lunsford, L.D. (2002a). Stereotactic radiosurgery for pilocytic astrocytomas when multimodal therapy is necessary. J. Neurosurg., 97:56-64

Hadjipanayis, C.G.; Niranjan, A.; Tyler-Kabara, E.; Kondziolka, D.; Flickinger, J.C. \& Lunsford, L.D. (2002b). Stereotactic radiosurgery for well-circumscribed fibrillary grade II astrocytomas: An initial experience. Stereotact. Funct. Neurosurg., 79:13-24 
Henderson, M.A.; Fakiris, A.J.; Timmerman, R.D.; Worth, R.M.; Lo, S.S. \& Witt, T.C. (2009). Gamma Knife stereotactic radiosurgery for low-grade astrocytomas. Stereotact. Funct. Neurosurg., 87:161-167

Heppner, P.A.; Sheehan, J.P. \& Steiner, L.E. (2005). Gamma Knife surgery for low-grade gliomas. Neurosurgery, 57:1132-1139

Hsieh, P.C.; Chandler, J.P.; Bhangoo, S.; Panagiotopoulos, K.; Kalapurakal, J.A.; Marymont, M.H. \& al. (2005). Adjuvant gamma knife stereotactic radiosurgery at the time of tumor progression potentially improves survival for patients with glioblastoma multiforme. Neurosurgery, 57:684-692

Jagannathan, J.; Petit, J.H.; Balsara, K.; Hudes, R. \& Chin, L.S. (2004). Long-term survival after gamma knife radiosurgery for primary and metastatic brain tumors. Am. J. Clin. Oncol., 27:441-444, ISSN 0277-3732/04/2705-0441

Jawahar, A.; Kondziolka, D.; Flickinger, J.C. \& Lunsford L.D. (1999). Adjuvant stereotactic radiosurgery for anaplastic ependymoma. Stereotact. Funct. Neurosurg., 73:23-30

Kano, H.; Kondziolka, D.; Niranjan, A.; Flickinger, J.C. \& Lunsford, L.D. (2009a). Stereotactic radiosurgery for pilocytic astrocytomas part 1: outcomes in adult patients. J. Neurooncol., 95:211-218

Kano, H.; Niranjan, A.; Khan, A.; Flickinger, J.C.; Kondziolka, D.; Lieberman, F. \& Lunsford, L.D. (2009c). Does radiosurgery have a role in the management of oligodendrogliomas? J. Neurosurg., 110:564-571

Kano, H.; Niranjan, A.; Kondziolka, D.; Flickinger, J.C. \& Lunsford, L.D. (2009d). Outcome predictors for intracranial ependymoma radiosurgery. Neurosurgery, 64:279-288

Kano, H.; Niranjan, A.; Kondziolka, D.; Flickinger, J.C.; Pollack, I.F.; Jakacki, R.L. \& Lunsford, L.D. (2009b). Stereotactic radiosurgery for pilocytic astrocytomas part 2: outcomes in pediatric patients. J. Neurooncol., 95:219-229

Kano, H.; Yang, H.C.; Kondziolka, D.; Niranjan, A.; Arai, Y.; Flickinger, J.C. \& Lunsford, L.D. (2010). Stereotactic radiosurgery for pediatric recurrent intracranial ependymomas. J. Neurosurg. Pediatrics, 6:417-423

Kohshi, K.; Yamamoto, H.; Nakahara, A.; Katoh, T. \& Takagi, M. (2007). Fractionated stereotactic radiotherapy using gamma knife unit after hyperbaric oxygenation on recurrent high-grade gliomas. J. Neurooncol., 82:297-303

Kong, D.S.; Lee, J.I.; Park, K.; Kim, J.H.; Lim, D.H. \& Nam, D.H. (2008). Efficacy of stereotactic radiosurgery as a salvage treatment for recurrent malignant gliomas. Cancer, 112:2046-2051

Kong, D.S.; Nam, D.H.; Lee, J.I.; Park, K. \& Kim, J.H. (2006). Preservation of quality of life by preradiotherapy stereotactic radiosurgery for unresectable glioblastoma multiforme. J. Neurosurg. (Suppl), 105:139-143

Krieger, M.D. \& McComb, J.G. (2009). The role of stereotactic radiotherapy in the management of ependymomas. Childs Nerv. Syst., 25:1269-1273

Kuo, J.S.; Yu, C.; Petrovich, Z. \& Apuzzo, M.L.J. (2003). The cyberknife stereotactic radiosurgery system: Description, installation, and an initial evaluation of use and functionality. Neurosurgery, 53:1235-1239 
Kurt, G.; Tönge, M.; Borcek, A.O.; Karahacioglu, E.; Gurel, O.; Baykaner, K. \& al. (2010). Fractionated gamma knife radiosurgery for optic nerve tumors: A technical report. Turkish Neurosurgery, 20 (2):241-246

Larson, D.A.; Prados, M.; Lamborn, K.R.; Smith, V.; Sneed, P.K.; Chang, S. \& al. (2002). Phase II study of high central dose gamma knife radiosurgery and marimastat in patients with recurrent malignant glioma. Int. J. Radiation Oncology Biol. Phys., 54:1397-1404

Lee, J.I.; Itasaka, S.; Kim, J.T. \& Nam, D.H. (2006). Antiangiogenic agent, thalidomide increases the antitumor effect of single high dose irradiation (gamma knife radiosurgery) in the rat orthotopic glioma model. Oncology Reports, 15:1163-1168

Lo, S.S.; Abdulrahman, R.; DesRosiers, P.M.; Fakiris, A.J.; Witt, T.C.; Worth, R.M. \& al. (2006a). The role of Gamma Knife radiosurgery in the management of unresectable gross disease or gross residual disease after surgery in ependymoma. Journal of Neuro-Oncology, 79:51-56

Lo, S.S.; Chang, E.L. \& Sloan, A.E. (2006b). Role of stereotactic radiosurgery and fractionated stereotactic radiotherapy in the management of intracranial ependymoma. Expert Rev. Neurotherapeutics, 6 (4):501-507, ISSN 1473-7175

Louis, D.N.; Ohgaki, H.; Wiestler, O.D. \& Cavenne, W.K. (Eds.) (2007). WHO Classification of Tumors of the Central Nervous System. IARC, ISBN 978-92-832-2430-2, Lyon, France

Mayer, R. \& Sminia, P. (2008). Reirradiation tolerance of the human brain. Int. J. Radiation Oncology. Biol. Phys., 70:1350-1360.

Morantz, A.R. (2001). Low grade astrocytomas, In: Brain Tumors; An encyclopedic approach, 2nd ed., A.H. Kaye \& E.R. Laws JR (eds.), 467-492, Churchill LivingstoneHarcourt, ISBN 0-433-06426-1, London, United Kingdom

Niranjan, A.; Moriuchi, S.; Lunsford, L.D.; Kondziolka, D.; Flickinger, J.C.; Fellows, W. \& al. (2000). Effective treatment of experimental glioblastoma by HSV vector-mediated TNFa and HSV-tk gene transfer in combination with radiosurgery and ganciclovir administration. Molecular Therapy, 2:114-120

Niyazi, M.; Siefert, A.; Schwarz, S.B.; Ganswindt, U.; Kreth, F.W.; Tonn, J.C. \& Belka, C. (2011). Therapeutic options for recurrent malignant glioma. Radiotherapy and Oncology, 98:1-14, ISSN 0167-8140

Oermann, E.; Collins, B.T.; Erickson, K.T.; Yu, X.; Lei, S.; Suy, S. \& al. (2010). CyberKnife® enhanced conventionally fractionated chemoradiation for high grade glioma in close proximity to critical structures. Journal of Hematology and Oncology, 3:22

Pantelis, E.; Papadakis, N.; Verigos, K.; Stathochristopoulou, I.; Antypas, C.; Lekas, L. \& al. (2010). Integration of functional MRI and white matter tractography in stereotactic radiosurgery clinical practice. Int. J. Radiation Oncology Biol. Phys., 78:257-267

Park, K.J.; Kano, H.; Kondziolka, D.; Niranjan, A.; Flickinger, J.C. \& Lunsford, L.D. (2010). Early or delayed radiosurgery for WHO grade II astrocytomas. Available from: http://www.springerlink.com/content/1686r1055h613182/ DOI 10.1007/s11060010-0409-0

Park, K.J.; Kano, H.K.; Kondziolka, D.; Niranjan, A.; Flickinger, J.C. \& Lunsford, L.D. (2011). Gamma Knife surgery for subependymal giant cell astrocytomas. J. Neurosurg., 114:808-813 
Patel, M.; Siddiqui, F.; Jin, J.Y.; Mikkelsen, T.; Rosenblum, M.; Movsas, B. \& Ryu, S. (2009). Salvage reirradiation for recurrent glioblastoma with radiosurgery: radiographic response and improved survival. J. Neurooncol., 92:185-191

Pollock, B.E. \& Brown, P.D. (2005). Stereotactic radiosurgery, In: Principles of Neurosurgery $2^{\text {nd }} E d$., S.S. Rengachary \& R.G. Ellenbogen (eds.), 729-740, Mosby-Elsevier, ISBN 07234-3222-8, London, United Kingdom

Pouratian, N.; Crowley, R.W.; Sherman, J.H.; Jagannathan, J. \& Sheehan, J.P. (2009). Gamma knife radiosurgery after radiation therapy as an adjunctive treatment for glioblastoma. J. Neurooncol., 94:409-418

Regis, J. (2009). Radiosurgery for intracranial tumors, In: Practical Handbook of Neurosurgery from Leading Neurosurgeons, M. Sindou (ed.), Vol.2:385-404, Springer-Verlag/Wien, ISBN 978-3-211-84819-7, Mörlenbach, Germany

Salvati, M.; Frati, A.; Russo, N.; Caroli, E.; Polli, F.M.; Minniti, G. \& Delfini, R. (2003). Radiation-induced gliomas: Report of 10 cases and review of the literature. Surg. Neurol., 60:60-67

Sarkar, A.; Pollock, B.E.; Brown, P.D. \& Gorman, D.A. (2002). Evaluation of gamma knife radiosurgery in the treatment of oligodendrogliomas and mixed oligoastrocytomas. J. Neurosurg., 97:653-656

Sathornsumetee, S. \& Rich, J.N. (2008). Designer therapies for glioblastoma multiforme. Ann. N. Y. Acad. Sci., 1140:108-132

Schwer, A.L.; Damek, D.M.; Kavanagh, B.D.; Gaspar, L.E.; Lillehei, K.; Stuhr, K. \& Chen, C. (2008). A phase I dose-escalation study of fractionated stereotactic radiosurgery in combination with gefitinib in patients with recurrent malignant gliomas. Int. J. Radiation Oncology. Biol. Phys., 70:993-1001

Sharma, M.; Kondziolka, D.; Khan, A.; Kano, H.; Niranjan, A.; Flickinger, J.C. \& Lunsford, L.D. (2008). Radiation tolerance limits of the brainstem. Neurosurgery, 63:728-733

Sloan, A.E.; Abdolvahavi, R. \& Hlatky, R. (2005). Gliomas, In: Principles of Neurosurgery 2nd Ed., S.S. Rengachary \& R.G. Ellenbogen (eds.), 451-478, Mosby-Elsevier, ISBN 07234-3222-8, London, United Kingdom

Smith, K.A.; Ashby, L.S.; Gonzalez, L.F.; Brachman, D.G.; Thomas, T.; Coons, S.W. \& al. (2008). Prospective trial of gross-total resection with gliadel wafers followed by early postoperative Gamma Knife radiosurgery and conformal fractionated radiotherapy as the initial treatment for patients with radiographically suspected, newly diagnosed glioblastoma multiforme. J. Neurosurgery, 109:106-117

Stieber, V.W. \& Ellis, T.L. (2005). The role of radiosurgery in the management of malignant brain tumors. Current Treatment Options in Oncology, 6:501-508, ISSN 1527-2729

Tsao, M.N.; Mehta, M.P.; Whelan, T.J.; Morris, D.E.; Hayman, J.A.; Flickinger, J.C. \& al. (2005). The American Society for Therapeutic Radiology and Oncology (ASTRO) evidence-based review of the role of radiosurgery for malignant glioma. Int. J. Radiation Oncology Biol. Phys., 63:47-55

Villavicencio, A.T.; Burneikiené, S.; Romanelli, P.; Fariselli, L.; McNeely, L.; Lipani, J.D. \& al. (2009). Survival following stereotactic radiosurgery for newly diagnosed and recurrent glioblastoma multiforme: a multicenter experience. Neurosurg. Rev., $32: 417-424$ 
Wang, L.W.; Shiau, C.Y.; Chung, W.Y.; Wu, H.M.; Guo, W.Y.; Liu, K.D. \& al. (2006). Gamma Knife surgery for low-grade astrocytomas: evaluation of long-term outcome based on a 10-year experience. J. Neurosurg., 105:127-132

Witham, T.F.; Okada, H.; Fellows, W.; Hamilton, R.L.; Flickinger, J.C.; Chambers, W.H. \& al. (2005). The characterization of tumor apoptosis after experimental radiosurgery. Stereotact. Funct. Neurosurg., 83:17-24

Xu, D.; Jia, Q.; Li, Y.; Kang, C. \& Pu, P. (2006). Effects of Gamma Knife surgery on C6 glioma in combination with adenoviral p53 in vitro and in vivo. J. Neurosurg., 105:208-213

Yen, C.P.; Sheehan, J.; Steiner, M.; Patterson, G. \& Steiner, L. (2007). Gamma Knife surgery for focal brainstem gliomas. J. Neurosurg., 106:8-17

Yoshikawa, K.; Saito, K.; Kajiwara, K.; Nomura, S.; Ishihara, H. \& Suzuki, M. (2006). CyberKnife stereotactic radiotherapy for patients with malignant glioma. Minim. Invas. Neurosurg., 49:110-115, ISSN 0946-7211 


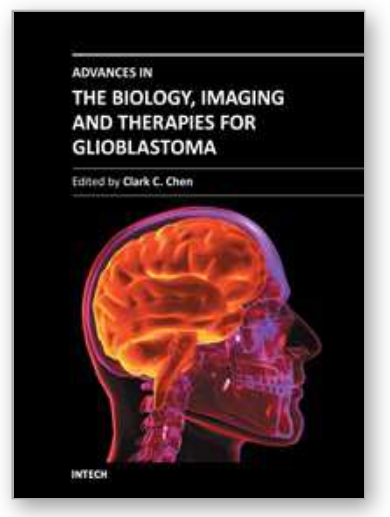

\author{
Advances in the Biology, Imaging and Therapies for Glioblastoma \\ Edited by Prof. Clark Chen
}

ISBN 978-953-307-284-5

Hard cover, 424 pages

Publisher InTech

Published online 09, November, 2011

Published in print edition November, 2011

This book is intended for physicians and scientists with interest in glioblastoma biology, imaging and therapy. Select topics in DNA repair are presented here to demonstrate novel paradigms as they relate to therapeutic strategies. The book should serve as a supplementary text in courses and seminars as well as a general reference.

\title{
How to reference
}

In order to correctly reference this scholarly work, feel free to copy and paste the following:

Mehmet Tönge and Gökhan Kurt (2011). Stereotactic Radiosurgery for Gliomas, Advances in the Biology, Imaging and Therapies for Glioblastoma, Prof. Clark Chen (Ed.), ISBN: 978-953-307-284-5, InTech, Available from: http://www.intechopen.com/books/advances-in-the-biology-imaging-and-therapies-forglioblastoma/stereotactic-radiosurgery-for-gliomas

\section{INTECH}

open science | open minds

\author{
InTech Europe \\ University Campus STeP Ri \\ Slavka Krautzeka 83/A \\ 51000 Rijeka, Croatia \\ Phone: +385 (51) 770447 \\ Fax: +385 (51) 686166 \\ www.intechopen.com
}

\author{
InTech China \\ Unit 405, Office Block, Hotel Equatorial Shanghai \\ No.65, Yan An Road (West), Shanghai, 200040, China \\ 中国上海市延安西路65号上海国际贵都大饭店办公楼 405 单元 \\ Phone: +86-21-62489820 \\ Fax: +86-21-62489821
}


(C) 2011 The Author(s). Licensee IntechOpen. This is an open access article distributed under the terms of the Creative Commons Attribution 3.0 License, which permits unrestricted use, distribution, and reproduction in any medium, provided the original work is properly cited. 